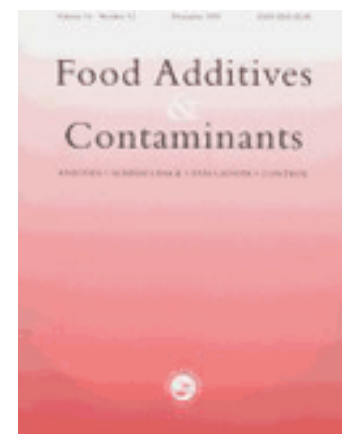

\title{
Modification of aflatoxin B1 and ochratoxin A toxicokinetics in rats administered a yeast cell wall preparation
}

\begin{tabular}{|c|c|}
\hline Journal: & Food Additives and Contaminants \\
\hline Manuscript ID: & TFAC-2009-399.R1 \\
\hline Manuscript Type: & Original Research Paper \\
\hline $\begin{array}{r}\text { Date Submitted by the } \\
\text { Author: }\end{array}$ & 25-Feb-2010 \\
\hline Complete List of Authors: & $\begin{array}{l}\text { Firmin, Stéphane; French Institute for Agricultural Research (INRA), } \\
\text { Herbivore Research Unit; Alltech-France, European Regulatory } \\
\text { Department } \\
\text { Gandia, Peggy; Laboratoire Cinétiques des Xénobiotiques, Faculté } \\
\text { des Sciences Pharmaceutiques, Université Paul Sabatier Toulouse } 3 \\
\text { Morgavi, Diego; French Institute for Agricultural Research (INRA), } \\
\text { Herbivore Research Unit } \\
\text { Houin, Georges; Laboratoire Cinétiques des Xénobiotiques, Faculté } \\
\text { des Sciences Pharmaceutiques, Université Paul Sabatier Toulouse } 3 \\
\text { jouany, JP; French Institute for Agricultural Research (INRA), } \\
\text { Herbivore Research Unit } \\
\text { Bertin, Gérard; Alltech-France, European Regulatory Department } \\
\text { Boudra, Hamid; French Institute for Agricultural Research (INRA), } \\
\text { Herbivore Research Unit }\end{array}$ \\
\hline Methods/Techniques: & Toxicology - pharmokinetics \\
\hline Additives/Contaminants: & Mycotoxins - aflatoxins, Mycotoxins - ochratoxin A \\
\hline Food Types: & Animal feed \\
\hline
\end{tabular}

\section{SCHOLARONEm Manuscripts}


Food Additives and Contaminants, Vol. X, No. X, Month 2009, 1-3

2 Modification of aflatoxin $B_{1}$ and ochratoxin A toxicokinetics in rats administered a yeast cell wall preparation

4

6 S. FIRMIN ${ }^{\mathrm{a}, \mathrm{b}}$, P. GANDIA ${ }^{\mathrm{c}}$, D.P. MORGAVI ${ }^{\mathrm{a}}$, G. HOUIN ${ }^{\mathrm{c}}$, J.P. JOUANY ${ }^{\mathrm{a}}$, G. BERTIN $^{\mathrm{b}}$ and H. BOUDRA ${ }^{\mathrm{a}}$

8

${ }^{a}$ INRA, UR1213, Unité de recherches sur les Herbivores, Centre de Clermont-Theix, F-63122 Saint Genès-

Champanelle, France ; ${ }^{b}$ Alltech-France, European Regulatory Department, F-92593 Levallois-Perret, France ;

${ }^{c}$ Laboratoire Cinétiques des Xénobiotiques, Faculté des Sciences Pharmaceutiques, Université Paul Sabatier

12 Toulouse 3, Toulouse 31062 cedex 9, France

*E-mail: $\underline{\text { hboudra@clermont.inra.fr }}$

ISSN 0165-0521 print/ISSN 1744-5140 online @ 2008 Taylor \& Francis DOI: 10.1080/XXXXXXXXXXXXXXXXX

http://www.informaworld.com 
A yeast product alters mycotoxins toxicokinetics 


\section{S. Firmin et al.}

\section{Introduction}

2

Mycotoxins are secondary fungal metabolites commonly found in foods and feeds (Placinta et al. 1999; Garon et al. 2006; Binder et al. 2007). Many of these secondary

4 metabolites are toxic to humans and animals, affecting health, reducing animal performance and causing substantial economic losses. The application of good agricultural and storage practices can reduce contamination but some factors contributing to fungal development, such as climatic conditions, are beyond human control and the absence of mycotoxins in the ration

8 of farm animals cannot be fully assured. The presence of mycotoxins in feeds is of concern in livestock production as it poses a risk for animals and also for consumers if toxic molecules 10 are transferred into animal products. In most countries contamination levels of aflatoxin $\mathrm{B}_{1}$ (AFB1) in feeds are regulated and thus, highly-contaminated feeds are not normally given to 12 animals. However, contamination levels just below the legal limit may still have a negative, long-term impact on production. In addition, on-farm produced feeds are seldom controlled,

14 which may result in higher than tolerable mycotoxin ingestion.

Several methods have been investigated for their capacity to remove, or reduce, 16 mycotoxins in contaminated feeds (reviewed by Jouany 2007). Some physical and chemical treatments such as the use of ammonia are expensive or simply not adapted to the treatment of 18 feeds destined for livestock (Niderkorn et al. 2007). The use of products, which could be defined as mycotoxins inactivators, to reduce absorption of mycotoxins in the gastrointestinal 20 tract of animals, is one such practical alternative which is currently receiving increased attention. Among these products, organic adsorbents such as yeast cell wall (YCW) have 22 been shown to rapidly form complexes in vitro with mycotoxins (Devegowda et al. 1998). Feeds multicontaminated by mycotoxins are frequent in the field (Scudamore et al. 1998; 24 Mansfield et al. 2008) and the ability of YCW to bind several mycotoxins makes them suitable for use under practical feeding conditions. In vivo studies have shown that YCW can 26 reduce the adverse effects of mycotoxins in different animal species; swine (Swamy et al. 2002), horse (Raymond et al. 2003), laying hens (Chowdhury et al. 2005), and dairy cows 28 (Korosteleva et al. 2007). In these studies the detoxification efficiency of YCW has been mainly evaluated on the basis of animal performance and/or the absence of toxicity, but the 30 precise mechanism responsible for the beneficial effect of this additive has not yet been clearly demonstrated. In lactating dairy cows receiving AFB1, a decrease in the excretion of 32 aflatoxin M1 in milk was observed in some studies (Diaz et al. 2004; Masoero et al. 2007) but 
not in others (Stroud 2006; Waltman 2008; Kutz et al. 2009). A decrease in milk carryover

2 suggests that mycotoxin absorption was impaired.

The purpose of this study was to evaluate the effect of a YCW-based preparation on AFB1 and ochratoxin A (OTA) toxicokinetics in rats. AFB1 and OTA were chosen as they are the two most common mycotoxins found in feeds and which can cause a variety of toxic

6 responses in animals, including nephrotoxic, hepatotoxic, teratogenic, and carcinogenic effects. Mycotoxins were ${ }^{3} \mathrm{H}$-labelled and radioactivity was monitored in faeces, urine and

8 plasma following oral administration. The YCW product was tested at two different doses and mycotoxins were used at relatively low concentrations and in a single dose $(<1 \%$ LD50) to prevent overt perturbations of liver and kidney functions.

\section{Materials and Methods}

\section{Chemicals}

Non-radioactive AFB1 and pentobarbital sodium were purchased from Sigma Chemical

14 (St Quentin, France). [ $\left.{ }^{3} \mathrm{H}\right]$-AFB1 (two different lots were used with a specific activity of 6.9 and $17.5 \mathrm{Ci} / \mathrm{mmol} ; 97 \%$ and $98.6 \%$ purity) and $\left[{ }^{3} \mathrm{H}\right]$-OTA (specific activity: $5 \mathrm{Ci} / \mathrm{mmol}$; $1699.6 \%$ purity) were supplied by Hartmann Analytic ( $\mathrm{GmbH}$, Braunschweig, Germany) in methanol and ethanol solutions, respectively. A stock solution of non radiolabelled AFB1 was

18 prepared in methanol at a concentration of $0.2 \mathrm{mg} / \mathrm{mL}$. Ready Safe ${ }^{\mathrm{TM}}$ LSC cocktail was supplied by Beckman Coulter (Villepinte, France), soluene-350 ${ }^{\circledR}$ by Perkin-Elmer

20 (Courtaboeuf, France). A preparation composed of modified cell walls extracts of Saccharomyces cerevisiae strain 1026 was provided by Alltech Inc. (Yeast Cell Wall (YCW), 22 purity 90\%, batch No FR71535-1, Nicholasville, U.S.A.). YCW was used as a suspension in $0.9 \% \mathrm{NaCl}$ at a concentration of $20 \mathrm{mg} / \mathrm{ml}$. Suspensions were freshly prepared before use.

\section{Animals and administration of mycotoxin}

26 Eight week-old male Sprague-Dawley $(265 \pm 30 \mathrm{~g})$ rats were purchased from Depré Centre (Saint-Doulchard, France). Rats had free access to water and were fed ad libitum with certified 2016 Teklad Global 16\% Protein Rodent Diet (Harlan Inc, WI, U.S.A.). The animal room was environmentally controlled, animals were provided with 12 hours light each day

30 with the temperature range maintained between 22 to $25^{\circ} \mathrm{C}$, and a relative humidity range of 40-55\%. Studies were conducted in accordance with the applicable national and European 


\section{S. Firmin et al.}

guidelines and regulations for experimentation with animals (see http://www2.vet-

2 lyon.fr/ens/expa/acc_regl.html for details).

Mycotoxins were administered by gavage through a gastric intubation at a constant

4 volume of $2 \mathrm{ml}$ of a dose solution per $\mathrm{kg}$ of BW. The exact amount administered was determined by weighing the dosing syringe before and after gavage. Feed was removed from

6 cages $12 \mathrm{~h}$ before gavage and rats were fed again $6 \mathrm{~h}$ post gavage. The dose solution contained AFB1 or OTA (specific activity: $40 \mu \mathrm{Ci} / \mathrm{kg}$ of BW) with or without YCW at one of

8 two concentrations. Stock mycotoxin solutions were diluted to the desired dose volume with $0.9 \% \mathrm{NaCl}$ and $0.1 \mathrm{M} \mathrm{NaHCO}_{3}$ for AFB1 and OTA, respectively. For the high dose of AFB1

$10(18.12 \mu \mathrm{g} / \mathrm{kg} \mathrm{BW})$ a 10 -fold isotopic dilution was prepared by co-diluting [ $\left.{ }^{3} \mathrm{H}\right]$-AFB1 (specific activity: $6.9 \mathrm{Ci} / \mathrm{mmol}$ ) with non radiolabelled AFB1. The YCW suspension was 12 replaced by a solution of $0.9 \% \mathrm{NaCl}$ in control animals.

\section{Study design}

A first assay using AFB1 was performed to optimize the protocol. In this trial a 16 comparison between the use of blood and plasma samples for monitoring absorption was made. Radioactivity in urine and faeces was monitored for up to 15 days to evaluate the 18 minimum collection time necessary to correctly assess excretion. Two groups of rats were included, each group was made up of 3 lots that received a single dose of AFB1 ( $40 \mu \mathrm{Ci}$ and

$2018.12 \mu \mathrm{g} / \mathrm{kg} \mathrm{BW}$ ) alone (lot 1) or in combination with YCW at $4 \mathrm{mg} / \mathrm{kg} \mathrm{BW}$ (lot 2) and 10 $\mathrm{mg} / \mathrm{kg} \mathrm{BW}$ (lot 3). In group 1, 12 rats (3 per lot) were randomly and individually placed in 22 metabolism cages (U.A.R., Epinay sur Orge, France). Urine and faeces were collected at 6, 12, 24, 36 and $48 \mathrm{~h}$, and then every $24 \mathrm{~h}$ up to 15 days post dose. Following each collection

24 cages were meticulously rinsed with water/methanol solution $(1 / 1 ; \mathrm{v} / \mathrm{v})$ and washing solutions collected in order to evaluate possible loss of radioactivity due to urine remaining within the 26 cages. Each sample (urine, faeces and recovered washings) were weighed and stored at - $20^{\circ}$ $\mathrm{C}$ until analysis. Animals were sacrificed by cervical dislocation following the last collection 28 of excreta. Liver, kidneys, jejunum, ileum and caecum of six animals (3 rats control and 3 rats YCW low dose) were dissected, weighed and aliquots were stored at $-20{ }^{\circ} \mathrm{C}$ until 30 analysis. Intestinal segments were processed without their contents. After sampling, viscera from each animal were regrouped with the carcass, homogenized and analyzed for total body 32 radioactivity.

In group 2 ( $\mathrm{n}=117 ; 39$ rats per lot) 3 rats were taken at each time point and anaesthetised 34 by an intraperitoneal injection of $50 \mathrm{mg} / \mathrm{kg} \mathrm{BW}$ sodium pentobarbital. Blood (approximately 
$3 \mathrm{~mL}$ ) was collected using the vacutainer ${ }^{\circledR}$ system (Beckson Dickinson) into heparinized tubes

2 (Beckson Dickinson) by ex-sanguination from the abdominal aortic vein at 0 (no toxin), 1, 2, $4,5,6,8,10,14,24,36,48$ and $72 \mathrm{~h}$ post dose. After sampling rats were euthanized. An

4 aliquot of blood was immediately used for analysis as described below. The remaining blood sample was centrifuged $\left(1000 \times g, 5 \mathrm{~min}\right.$ at $\left.4{ }^{\circ} \mathrm{C}\right)$ and the plasma fraction decanted into clean 6 tubes and stored at $-20^{\circ} \mathrm{C}$ until analysis.

Based on this first study with AFB1 a good correlation between plasma and blood 8 samples was established, only plasma samples were collected on the second AFB1 and OTA studies. In addition, in the second study urine and faeces were collected for three days, as the 10 bulk of the radioactivity was recovered within the first $72 \mathrm{~h}$ post dosing.

The second AFB1 experiment was conducted using a lower dose $(0.716 \mu \mathrm{g} / \mathrm{kg} \mathrm{BW})$, 12 which was provided by $\left[{ }^{3} \mathrm{H}\right]-\mathrm{AFB} 1$ alone (specific activity: $17.5 \mathrm{Ci} / \mathrm{mmol}$ ). This dose, when extrapolated to livestock species is in line with the European Community limitation of 0.02 $14 \mathrm{mg} / \mathrm{kg}$ feed (directive 2003/100/EC). In a similar way, doses of YCW were 16.4 and 65.7 $\mathrm{mg} / \mathrm{kg} \mathrm{BW}$, which were within the range recommended by the YCW manufacturer for 16 different livestock species when calculated based on their inclusion in feed. For the excretion study, 15 rats were used (5 per lot) and urine and faeces were collected at 6, 12, 24, 36, 48 18 and $72 \mathrm{~h}$ post dosing. For the absorption study $(\mathrm{n}=117 ; 39$ rats per lot), plasma was obtained and stored as described above at 0 (no toxin), 1, 2, 4, 5, 6, 8, 10, 14, 24, 36, 48 and $72 \mathrm{~h}$ post 20 dose.

The OTA study was similar to the second AFB1 study with 15 (5 per lot) and 63 rats (21 22 per lot) used for excretion and plasma measurements, respectively. Urine was collected for 3 days and faeces for 10 days. OTA was used at a dose of $3.22 \mu \mathrm{g} / \mathrm{kg}$ BW for a total 24 radioactivity of $40 \mu \mathrm{Ci}$ per rat as described above.

\section{Sample preparation and analysis}

Before analysis faecal samples were homogenized in distilled water, $10 \%$ (w/w) dilution. 28 Faecal homogenates $(50 \mathrm{mg})$ were incubated at $50{ }^{\circ} \mathrm{C}$ overnight with $1 \mathrm{ml}$ of soluene ${ }^{\circledR}$ isopropanol solution $(1 / 1 ; \mathrm{v} / \mathrm{v})$ and $0.5 \mathrm{ml}$ of $30 \%$ hydrogen peroxide. Blood samples $(50 \mu \mathrm{l})$

30 were treated as faecal samples but were processed immediately after collection in order to minimize non-radioactive scintillation counting. All samples, i.e. blood, faecal homogenate, 32 urine $(100 \mu \mathrm{l})$, plasma $(100 \mu \mathrm{l})$, and wash water from metabolic cages were mixed with $10 \mathrm{ml}$ of Ready Safe ${ }^{\mathrm{TM}}$ scintillation fluid and stabilized overnight in the dark before counting the 


\section{S. Firmin et al.}

radioactivity in a LS 1801 scintillation counter (Beckman Coulter, Villepinte, France). All

2 samples were analyzed in triplicate, except for blood samples that were analyzed in duplicate.

Tissue radioactivity was measured by liquid scintillation counting after oxidative

4 combustion with an oxidizer (Packard 306 Oxidizer, Packard Instruments, Meridien, CT, USA), using Permafluor E+ MonophaseS ${ }^{\circledR}$ (Packard Instruments) as the scintillation cocktail.

6 Viscera and carcase samples (200 mg) were packed into cellulose combustion cones imbibed with $100 \mu \mathrm{l}$ of an organic-based combustion aid solution Combustaid ${ }^{\circledR}$ (Packard Instruments)

8 and were analyzed in triplicate and quadruplicate, respectively.

\section{Toxicokinetics and statistical data analysis}

Non-compartmental methods were used to estimate the toxicokinetic parameters of 12 radiolabelled mycotoxins. The parameters $C_{\max }$ and $T_{\max }$ were observed values defined as the highest concentration achieved and the required time to achieve it, respectively. $\mathrm{AUC}_{0 \text {-last }}$ was

14 the area under plasma concentration versus time curve, calculated by the trapezoidal method between the first and the last measurable concentration. $\mathrm{AUC}_{0-\propto}$ was the $\mathrm{AUC}_{0 \text {-last }}$

16 extrapolated to infinity by the ratio of the last measurable concentration to the terminal slope $k_{e}$. Elimination constant $\left(k_{e}\right)$ was determined by using the Kinetica software (InnaPhase, 18 Champ-sur-Marne, France, release 4.0). $T_{1 / 2}$ corresponds to the terminal half-life determined as the ratio of Neperian logarithm of 2 to the terminal slope $\left(k_{e}\right)$. Due to the experimental 20 design, it was not possible to conduct a statistical analysis directly on the kinetic parameters (Lellouch, Lazar 1996). Samples for toxicokinetic parameters calculation were obtained from 22 three different rats at each sampling time. Radioactivity values measured in plasma and blood were compared at each sampling time using non-parametric, one-way-analysis of variance

24 (Kruskal-Wallis test) using SAS version 8 (SAS Institute Inc., Cary, NC). The Kruskal-Wallis test was also used to analyse excretion data (urine and faeces). Significance was declared at 26 the 5\% probability level.

\section{Results}

28 No overt toxic effects, sickness or behavioural anomalies were observed in any animals in any of the studies. In the first AFB1 study radioactivity values for plasma samples were

30 about half that of blood, but profiles were similar between both matrices (data not shown). Although the recovery was lower with plasma, this matrix was used in subsequent studies 32 because, unlike blood, plasma samples could be stored and analysed all at the same time. 
$21.3 \%$, which did not represent a large proportion of the total. In faeces it represented a larger fraction of approximately $15 \%$. In both cases, however, no differences were observed between treatments ( $p>0.05$; data not shown), justifying the $72 \mathrm{~h}$ collection period of later studies following gavage administration.

Data from all three studies are presented in Tables 1 and 2, but results in the text for AFB1 refer to the low dose study unless otherwise stated. Toxicokinetic parameters are summarized in Table 1 with an example of plasma profiles for $\left[{ }^{3} \mathrm{H}\right]$-AFB1 (Figure 1). Radioactivity from AFB1 was detected $1 \mathrm{~h}$ after dosing, reaching a maximum value at 4 to $5 \mathrm{~h}$ post dosing and decreasing slowly thereafter with an elimination half-life $\left(T_{1 / 2}\right)$ of about $64 \mathrm{~h}$. The combination of YCW with $\left[{ }^{3} \mathrm{H}\right]$-AFB1 altered plasma profiles, namely the absorption phase, irrespective of YCW dose. This decrease in the oral bioavailable fraction of AFB1 was not accompanied by modifications of the absorption rate. $C_{\max }$ and AUC were lower in 4 YCW treated lots when compared to values obtained in respective control groups. The average decrease of $\mathrm{AUC}_{0-\infty}$ after co-administration of $\mathrm{YCW}$ was approximately $38 \%$ and was independent of dose, except for high YCW at the high AFB1 concentration which resulted in a less marked decrease (Table 1$)$. In contrast, the parameters of elimination phase $\left(T_{1 / 2}\right.$ and $\left.k_{\mathrm{e}}\right)$ were not influenced by YCW co-administration.

The excretion balance in the presence of YCW (Table 2) was in agreement with the changes observed in the plasma toxicokinetic parameters. Urinary excretion of radioactivity was lower after co-administration of YCW $(p<0.05)$, while faecal excretion increased $(p<$ 0.05 ) (Table 2). Excretion in faeces increased by as much as $55 \%$ when compared to controls without YCW. The level of YCW inclusion did not have any effect on radioactivity excretion.

In the OTA study this toxin reached a higher maximum concentration than AFB1 in 26 plasma, resulting in higher calculated AUC parameters (Table 1). In contrast, the YCW treatment showed a less perceptible effect during the absorption phase. In YCW treated 28 animals OTA concentration in plasma was lower than control animals $1 \mathrm{~h}$ after gavage $(p<$ 0.05). However, beyond $1 \mathrm{~h}$ post-gavage OTA concentrations were the same in all three 30 groups $(p>0.05)$. Although the YCW treatment did not affect urinary excretion, it increased toxin elimination in faeces $(p<0.05$; Table 2$)$. However, this increase was less marked than AFB1, approximately $15 \%$ compared to $55 \%$ for the latter.

Metabolic cages were rinsed and the wash water counted to address the possibility that urine was not fully collected and a proportion of urinary radioactivity was unaccounted for. 


\section{S. Firmin et al.}

Cage contamination was $1.3 \%, 3.3 \%$ and $5.2 \%$ of the total radioactivity excreted for the low-

2 AFB1, high-AFB1 and OTA experiments, respectively (Table 2)(data not shown). Whether these values were added to the urine radioactivity or not did not affect the results. The effect

4 of YCW on the level of radioactivity accumulating in rats was assayed using animals from the first AFB1 experiment. At 15 days post-treatment the residual radioactivity in the carcasses

6 of the control group was $2.5 \% \pm 0.68$ (mean $\pm \mathrm{SD}$ ) compared to $1.6 \% \pm 0.41$ for the low YCW group $(p=0.12)$. Trace amounts of radioactivity $(0.005 \%)$ were found in kidneys and

8 different segments of the gastrointestinal tract. The liver accounted for the bulk of viscera radioactivity with $0.31 \% \pm 0.034$ and $0.19 \pm 0.082$ for control and YCW group, respectively

$10 \quad(p<0.05)$.

\section{Discussion}

12 Mycotoxin sequestration in the gastrointestinal tract by adsorbing agents such as yeast cell walls could be a promising strategy to protect against the toxic effect of these feed 14 contaminants. However, there is still scarce information on their effect in vivo. Recent reports indicate a positive effect on animal production performance and a reduction of 16 mycotoxin carryover into milk (Diaz et al. 2004; Chowdhury et al. 2005; Korosteleva et al. 2007; Masoero et al. 2007). In contrast, the use of these kind of additives do not always result 18 in a positive effect on the parameter measured (Stroud 2006; Waltman 2008; Kutz et al. 2009). The type of yeast could be at the origin of these differences among studies. The cell

20 wall polysaccharide responsible for mycotoxin binding such as the alkali insoluble fraction of $\beta$-D-glucans (Yiannikouris et al. 2004b) varies in quality and quantity between species and 22 strains (Nguyen et al. 1998). In addition, it has been described that for a same strain the growth conditions and the preparation process influence the adsorption capacity of yeast cell 24 wall additives (Pradelles et al. 2008). The inconsistency between studies, however, could also be due to other reasons such as the mode of incorporation of the preparation into the diet or by

26 the type of feed and mycotoxin present (Battacone et al. 2009; Blank, Wolffram 2009; Masoero et al. 2009). Trials involving domestic animals involve many variables which are 28 difficult to control between studies. The lack of a positive response reported in some trials using these mycotoxin adsorbing agents has also been reported for other widely used feed 30 additives such as probiotics or feed enzymes (Beauchemin et al. 2003; Robinson, Erasmus 2009). It is clear that more studies are needed to better understand the underlying factors inducing this variability and correctly evaluate their efficacy. 
The present study, using a rat animal model, shows that a preparation exclusively 2 composed of yeast cell walls extracted from Saccharomyces cerevisiae strain 1026 significantly reduces intestinal absorption of AFB1. It is worth mentioning that in the toxicokinetic model used, rats were in a fasted state when the mycotoxin-YCW mixture was administered. Under natural conditions mycotoxins are contained in feeds and it is known

6 that the presence of feeds in the gastrointestinal tract may affect the bioavailability of different xenobiotic molecules (Wonnemann et al. 2006; Disanto, Golden 2009).

The toxicokinetics of AFB1 and OTA were investigated using low mycotoxin doses. These doses were calculated based on the maximum concentrations allowed or tolerated in animal feeds by the European legislation (2002/32/CE and 2006/576/CE). In addition, these low doses are equivalent, in mg per $\mathrm{kg} \mathrm{BW}$, to the quantity that could be ingested by farm 12 animals under normal production conditions. Although these mycotoxins have never been investigated in rats at such low oral levels blood and/or plasma kinetics of both toxins were in

14 agreement with previous reports. Galtier et al., (1979) and Coulombe and Sharma (1985) observed a biological half life of $55 \mathrm{~h}$ for OTA and 91.8 h for AFB1 (vs 63-65 h and 50-65h 16 in the present study) following the oral administration of unlabeled OTA $2.5 \mathrm{mg} \mathrm{kg}^{-1} \mathrm{BW}$ and $\left[{ }^{3} \mathrm{H}\right]$-AFB1 $600 \mu \mathrm{g} \mathrm{kg}^{-1} \mathrm{BW}$, respectively. The peak of radioactivity in blood was reached between 1 and $4 \mathrm{~h}$ following unlabeled OTA oral administration (Suzuki et al. 1977) and that of ${ }^{14} \mathrm{C}$-AFB1 in plasma was reached $1 \mathrm{~h}$ after the same mode of administration (Wong, Hsieh 20 1978). Discrepancies with literature data were minor and may be due to differences in protocol design.

22 In the current study results from toxicokinetic parameters indicate that the YCW treatment modified the absorption phase. The AUC decreased in the YCW treated groups 24 whereas the $K_{e}$ was similar in all groups. In addition, the increase in cumulative radioactivity in faecal material was associated with a decrease in cumulative urinary excretion, mainly for

26 AFB1 treatments. At the end of the experiment, up to $64 \%$ and $51 \%$ of total radioactivity was recovered in urine and faeces for AFB1 and OTA, respectively. This amount of recovery is 28 normally found with tritium labelled molecules administered at very low levels (Beumer et al. 2006). Recovery can be improved if the radioactivity recovered from cages by washing and,

30 in the case of the first AFB1 experiment, the radioactivity fixed in the carcasses at the end of the trial is included in the calculation. Residual activity in carcasses of animals $360 \mathrm{~h}$ after

32 administration of AFB1 was low indicating that a significant amount was eliminated by an alternative route. Other studies also reported a partial recovery of the total administrated 34 radioactivity (Suzuki et al. 1977; Galtier et al. 1979; Coulombe, Sharma 1985; Kumagai et al. 


\section{S. Firmin et al.}

1998), which could be explained by toxin retention within the kidneys in the case of OTA

2 (Zepnik et al. 2003), or in liver in the case of AFB1 (Wogan et al. 1967) and by exhalation of tritiated water generated by exchange of the labelled ${ }^{3} \mathrm{H}$ (Beumer et al. 2006). In our study

4 with tritiated toxins, this latter route of elimination of radioactivity was highly probable.

In vitro studies demonstrated the adsorption of different mycotoxins such as AFB1 and

6 OTA to viable cultures of Saccharomyces cerevisiae (Devegowda et al. 1994; Meca et al. in press). Preparations containing $\beta$-D-glucans portions of the specific strain 1026 exhibited a

8 strong binding capacity in vitro for aflatoxins (up to 85\%) while being poorer at sequestering OTA (12.4\%) (Devegowda et al. 1998). Also, the extent of complexation, i.e. AFB1 > OTA,

10 was not altered by $\mathrm{pH}$ values that are close to those found within the digestive tract (Yiannikouris et al. 2006). The in vitro binding affinity is in agreement with the in vivo

12 results observed here in rats, further supporting the hypothesis that binding is a key property involved in the toxicity-alleviating effects of YCW.

14 Conversely, no dose effect of YCW was observed in the present study. A possible reason for this result could be the low level of mycotoxin used. The adsorptive capacity of yeast $\beta$ -

16 D-glucans in vitro was shown to be modulated by the amount of mycotoxins added to the medium according to a cooperative phenomenon. Binding of the first mycotoxin molecules

18 induce conformation changes in $\beta$-glucans that facilitates access to new sites of fixation improving binding efficiency until saturation of all sites of adsorption (Yiannikouris et al.

20 2003; Yiannikouris et al. 2004a). In our study, toxin molecules were highly diluted and the minimum level of physical contacts capable to produce cooperative interactions was probably 22 not fully achieved independently of YCW concentration.

The present study was based on measurements of radioactivity alone and provides no 24 information on proportion of parent compounds and their metabolic products recovered in blood, faeces, urine or carcasses. It has to be noted that some of the radioactivity found in 26 faeces in the first hours following administration could have been originated from liverconjugated metabolites (Ha et al. 1999; Gross-Steinmeyer et al. 2002), particularly for AFB1, 28 that are eliminated via the bile (Bassir, Osiyemi 1967; Kumagai, Aibara 1982). Nonetheless, the decreased absorption and increased excretion observed in our experimental model 30 indicates that the tested preparation may have the potential to protect monogastric animals against exposure to low dietary levels of selected mycotoxins. 
A yeast product alters mycotoxins toxicokinetics

\section{Acknowledgments}

2

S. Firmin was supported by a doctoral fellowship (CIFRE 1058/2007), jointly financed by the Alltech company, ANRT (Association Nationale de la Recherche Technique) and

4 INRA (Institut National de la Recherche Agronomique). We would like to thank Prof. J. Woodley for his help with the English language and Dr J.P. Cravedi from the laboratory of 6 Xenobiotics INRA-Toulouse for facilitating the analysis of carcasses. 


\section{S. Firmin et al.}

\section{References}

2 Bassir O, Osiyemi F. 1967. Biliary excretion of aflatoxin in the rat after a single dose. Nature. 215:882.

Battacone G, Nudda A, Palomba M, Mazzette A, Pulina G. 2009. The transfer of aflatoxin M1 in milk of ewes fed diet naturally contaminated by aflatoxins and effect of inclusion of dried yeast culture in the diet. J Dairy Sci. 92:4997-5004.

Beauchemin KA, Colombatto D, Morgavi DP, Yang WZ. 2003. Use of Exogenous Fibrolytic Enzymes to Improve Feed Utilization by Ruminants. J Anim Sci. 81:E37-47.

Beumer JH, Beijnen JH, Schellens JHM. 2006. Mass balance studies, with a focus on anticancer drugs. Clin Pharmacokinet. 45:33-58.

Binder EM, Tan LM, Chin LJ, Handl J, Richard J. 2007. Worldwide occurrence of mycotoxins in commodities, feeds and feed ingredients. Anim Feed Sci Technol. 137:265-282.

Blank R, Wolffram S. 2009. Effects of live yeast cell supplementation to high concentrate diets on the toxicokinetics of ochratoxin A in sheep. Food Addit Contam Part A Chem Anal Control Expo Risk Assess. 26:119-126.

Chowdhury SR, Smith TK, Boermans HJ, Woodward B. 2005. Effects of feed-borne Fusarium mycotoxins on hematology and immunology of laying hens. Poult Sci. 84:1841-1850.

Coulombe RA, Jr., Sharma RP. 1985. Clearance and excretion of intratracheally and orally administered aflatoxin B1 in the rat. Food Chem Toxicol. 23:827-830.

Devegowda G, Aravind B, Nazar A, Rajendra K, Morton M, Baburathna A, Sudarshan C. 1994. A biological approach to counteract aflatoxicosis in broiler chickens and ducklings by the use of Saccharomyces cerevisiae cultures added to feed. Paper presented at: Biotechnology in the feed industry Proceedings of Alltech's 10th Annual Symposium Loughborough, Nottingham University Press.

Devegowda G, Raju MVLN, Nazar A, Swamy HVLN. 1998. Mycotoxin picture worldwide: novel solutions for their counteraction. Biotechnology in the feed industry Proceedings of Alltech's 14th Annual Symposium: passport to the year 2000 p. 241255.

Diaz DE, Hagler WM, Jr., Blackwelder JT, Eve JA, Hopkins BA, Anderson KL, Jones FT, Whitlow LW. 2004. Aflatoxin binders II: reduction of aflatoxin M1 in milk by sequestering agents of cows consuming aflatoxin in feed. Mycopathologia. 157:233241.

Disanto AR, Golden G. 2009. Effect of food on the pharmacokinetics of clozapine orally disintegrating tablet $12.5 \mathrm{mg}$ : a randomized, open-label, crossover study in healthy male subjects. Clin Drug Investig. 29:539-549.

Galtier P, Charpenteau JL, Alvinerie M, Labouche C. 1979. The pharmacokinetic profile of ochratoxin A in the rat after oral and intravenous administration. Drug Metab Dispos. 7:429-434.

Garon D, Richard E, Sage L, Bouchart V, Pottier D, Lebailly P. 2006. Mycoflora and multimycotoxin detection in corn silage: Experimental study. J Agric Food Chem. 54:3479-3484.

Gross-Steinmeyer K, Weymann J, Hege H-G, Metzler M. 2002. Metabolism and lack of DNA reactivity of the mycotoxin ochratoxin $\mathrm{A}$ in cultured rat and human primary hepatocytes. J Agric Food Chem. 50:938-945.

Ha TG, Mar WC, Kim SG, Surh Y-J, Kim ND. 1999. Enhancement of biliary excretion of aflatoxin B1 and suppression of hepatic ornithine decarboxylase activity by 2(allylthio)pyrazine in rats. Mutat Res. 428:59-67. 
Jouany JP. 2007. Methods for preventing, decontaminating and minimizing the toxicity of mycotoxins in feeds. Anim Feed Sci Technol. 137:342-362.

Korosteleva SN, Smith TK, Boermans HJ. 2007. Effects of feedborne Fusarium mycotoxins on the performance, metabolism, and immunity of dairy cows. J Dairy Sci. 90:38673873.

Kumagai S, Aibara K. 1982. Intestinal absorption and secretion of ochratoxin A in the rat. Toxicol Appl Pharmacol. 64:94-102.

Kumagai S, Sugita-Konishi Y, Hara-Kudo Y, Ito Y, Noguchi Y, Yamamoto Y, Ogura A. 1998. The fate and acute toxicity of aflatoxin B1 in the mastomys and rat. Toxicon. 36:179-188.

Kutz RE, Sampson JD, Pompeu LB, Ledoux DR, Spain JN, Vazquez-Anon M, Rottinghaus GE. 2009. Efficacy of Solis, NovasilPlus, and MTB-100 to reduce aflatoxin M1 levels in milk of early to mid lactation dairy cows fed aflatoxin B1. J Dairy Sci. 92:39593963.

Lellouch J, Lazar P. 1996. Méthodes statistiques en expérimentation biologique. Paris, France: Flammarion.

Mansfield MA, Jones AD, Kuldau GA. 2008. Contamination of fresh and ensiled maize by multiple Penicillium mycotoxins. Phytopathology. 98:330-336.

Masoero F, Gallo A, Diaz D, Piva G, Moschini M. 2009. Effects of the procedure of inclusion of a sequestering agent in the total mixed ration on proportional aflatoxin M1 excretion into milk of lactating dairy cows. Anim Feed Sci Technol. 150:34-45.

Masoero F, Gallo A, Moschini M, Piva G, Diaz D. 2007. Carryover of aflatoxin from feed to milk in dairy cows with low or high somatic cell counts. Animal. 1:1344-1350.

Meca G, Blaiotta G, Ritieni A. in press. Reduction of ochratoxin A during the fermentation of Italian red wine Moscato. Food Control.

Nguyen TH, Fleet GH, Rogers PL. 1998. Composition of the cell walls of several yeast species. Appl Microbiol Biotechnol. 50:206-12.

Niderkorn V, Boudra H, Morgavi DP. 2007. Les fusariotoxines: comment limiter leur presence dans les ensilages et leur impact chez les ruminants? Fourrages.111-123.

Placinta CM, D'Mello JPF, Macdonald AMC. 1999. A review of worldwide contamination of cereal grains and animal feed with Fusarium mycotoxins. Anim Feed Sci Technol. 78:21-37.

Pradelles R, Alexandre H, Ortiz-Julien A, Chassagne D. 2008. Effects of yeast cell-wall characteristics on 4-ethylphenol sorption capacity in model wine. J Agric Food Chem. 56:11854-61.

Raymond SL, Smith TK, Swamy HV. 2003. Effects of feeding a blend of grains naturally contaminated with Fusarium mycotoxins on feed intake, serum chemistry, and hematology of horses, and the efficacy of a polymeric glucomannan mycotoxin adsorbent. J Anim Sci. 81:2123-2130.

Robinson PH, Erasmus LJ. 2009. Effects of analyzable diet components on responses of lactating dairy cows to Saccharomyces cerevisiae based yeast products: A systematic review of the literature. Anim Feed Sci Technol. 149:185-198.

Scudamore KA, Nawaz S, Hetmanski MT. 1998. Mycotoxins in ingredients of animal feeding stuffs: II. Determination of mycotoxins in maize and maize products. Food Addit Contam. 15:30-55.

Stroud JS, 2006, The effect of feed additives on aflatoxin in milk of dairy cows fed aflatoxincontaminated diets. Graduate Faculty of North Carolina State University Thesis (Raleigh: North Carolina State University), pp. 46.

Suzuki S, Satoh T, Yamazaki M. 1977. The pharmacokinetics of ochratoxin A in rats. Jpn J Pharmacol. 27:735-744. 


\section{S. Firmin et al.}

Swamy HV, Smith TK, MacDonald EJ, Boermans HJ, Squires EJ. 2002. Effects of feeding a blend of grains naturally contaminated with Fusarium mycotoxins on swine performance, brain regional neurochemistry, and serum chemistry and the efficacy of a polymeric glucomannan mycotoxin adsorbent. J Anim Sci. 80:3257-67.

Waltman L, 2008, Effect of sequestering agents on aflatoxin in milk of dairy cows fed aflatoxin-contaminated diets. Graduate Faculty of North Carolina State University Thesis (Raleigh: North Carolina State University), pp. 108.

Wogan GN, Edwards GS, Shank RC. 1967. Excretion and tissue distribution of radioactivity from aflatoxin $\mathrm{B} 1-{ }^{14} \mathrm{C}$ in rats. Cancer Res. 27:1729-1736.

Wong ZA, Hsieh DP. 1978. Aflatoxicol: major aflatoxin B1 metabolite in rat plasma. Science. 200:325-7.

Wonnemann M, Schug B, Schmucker K, Brendel E, van Zwieten PA, Blume H. 2006. Significant food interactions observed with a nifedipine modified-release formulation marketed in the European Union. Int J Clin Pharmacol Ther. 44:38-48.

Yiannikouris A, Andre G, Poughon L, Francois J, Dussap CG, Jeminet G, Bertin G, Jouany JP. 2006. Chemical and conformational study of the interactions involved in mycotoxin complexation with beta-D-glucans. Biomacromolecules. 7:1147-1155.

Yiannikouris A, Francois J, Poughon L, Dussap CG, Bertin G, Jeminet G, Jouany JP. 2004a. Adsorption of zearalenone by $\beta$-D-glucans in the Saccharomyces cerevisiae cell wall. J Food Prot. 67:1195-200.

Yiannikouris A, Francois J, Poughon L, Dussap CG, Bertin G, Jeminet G, Jouany JP. 2004b. Alkali extraction of $\beta$-D-glucans from Saccharomyces cerevisiae cell wall and study of their adsorptive properties toward zearalenone. J Agric Food Chem. 52:3666-3673.

Yiannikouris A, Poughon L, Cameleyre X, Dussap CG, Francois J, Bertin G, Jouany JP. 2003. A novel technique to evaluate interactions between Saccharomyces cerevisiae cell wall and mycotoxins: application to zearalenone. Biotech Lett. 25:783-789.

Zepnik H, Volkel W, Dekant W. 2003. Toxicokinetics of the mycotoxin ochratoxin A in F 344 rats after oral administration. Toxicol Appl Pharmacol. 192:36-44. 
2 Table 1. Mean toxicokinetic parameters in plasma after a single dose of aflatoxin B1 at two concentrations and ochratoxin A with and without co-administration of a yeast cell wall preparation in rats

4

\begin{tabular}{|c|c|c|c|c|c|c|c|c|c|}
\hline \multirow[b]{2}{*}{ Parameters } & \multicolumn{3}{|c|}{ Aflatoxin B1 (18.12 $\mu \mathrm{g} / \mathrm{kg} \mathrm{BW})$} & \multicolumn{3}{|c|}{ Aflatoxin B1 $(0.716 \mu \mathrm{g} / \mathrm{kg} \mathrm{BW})$} & \multicolumn{3}{|c|}{ Ochratoxin A (3.22 $\mu \mathrm{g} / \mathrm{kg} \mathrm{BW})$} \\
\hline & Control & YCW-L & YCW-H & Control & YCW-L & YCW-H & Control & YCW-L & YCW-H \\
\hline Cmax (ng/ml/kg BW) & 3.66 & 1.91 & 2.26 & 0.72 & 0.27 & 0.35 & 28.78 & 20.84 & 21.47 \\
\hline $\operatorname{Tmax}(h)$ & 4.0 & 4.0 & 4.0 & 4.0 & 5.0 & 4.0 & 5.0 & 5.0 & 5.0 \\
\hline K-elimination $\left(\mathbf{h}^{-1}\right)$ & 0.01 & 0.01 & 0.01 & 0.01 & 0.01 & 0.01 & 0.01 & 0.01 & 0.01 \\
\hline $\mathbf{T}_{1 / 2}(\mathbf{h})$ & 53.3 & 55.5 & 53.7 & 63.6 & 65.4 & 65.4 & 63.6 & 65.4 & 65.4 \\
\hline AUC 0-72h(ng/ml/kg BW) & 129.0 & 82.4 & 111.0 & 32.4 & 19.8 & 19.9 & 1731.3 & 1260.6 & 1337.9 \\
\hline 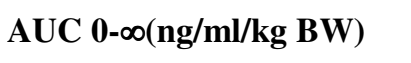 & 131.4 & 83.9 & 113.1 & 32.9 & 20.1 & 20.2 & 1758.5 & 1279.8 & 1358.4 \\
\hline$\triangle \mathrm{AUC} 0-\infty(\%)$ & & 36.1 & 13.9 & & 38.9 & 38.9 & & 27.2 & 22.8 \\
\hline
\end{tabular}

$C_{\max }=$ maximum plasma concentration; $t_{\max }=$ time to reach $C_{\max } ; \mathrm{K}$-elimination = elimination constant; $\mathrm{T}_{1 / 2}=$ terminal elimination half-life; AUC $=$ area under the plasma concentration versus time curve from 0 to $72 \mathrm{~h}, 72$ to infinite, and 0 to infinite, respectively. Pharmakinetic parameters were calculated from a concentration-time curve made from samples obtained from three different rats at each sampling point except for $C_{\max }$ and $t_{\max }$ which are the mean of all $C_{\max }$ and $t_{\max }$ values obtained. 


\section{S. Firmin et al.}

Table 2. Cumulative excretion of mycotoxins after a single dose of aflatoxin B1 at two concentrations and ochratoxin A with and without co2 administration of a yeast cell wall preparation in rats

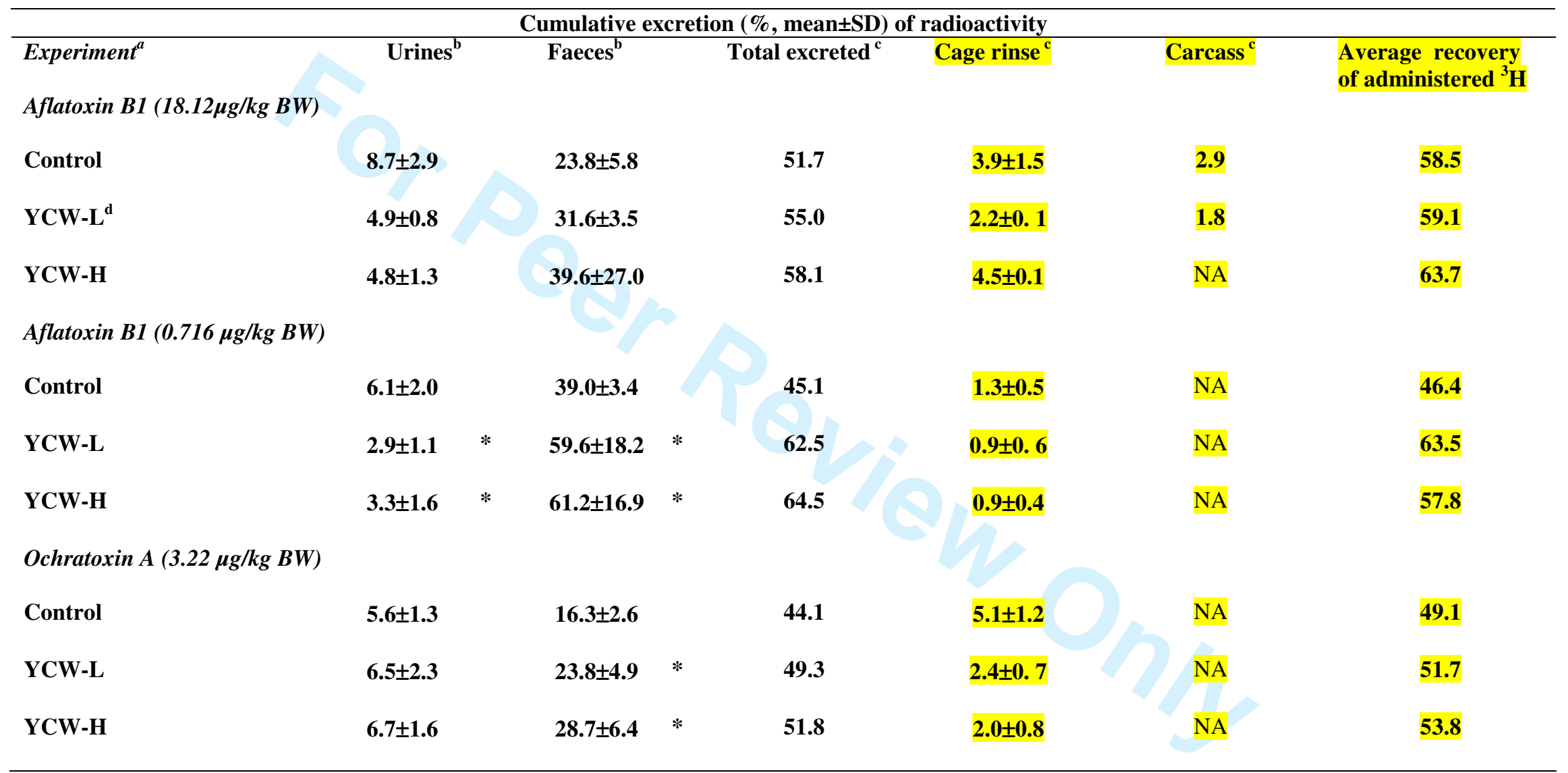

$4{ }^{a}$ values are means $\pm \mathrm{SD}, \mathrm{n}=5$ rats, except for aflatoxin $\mathrm{B} 1(18.12 \mu \mathrm{g} / \mathrm{kg}$ body weigth $(\mathrm{BW}))$ where 3 rats were used.

${ }^{\mathrm{b}}$ Excreted at $72 \mathrm{~h}$

$6{ }^{\mathrm{c}}$ Recovered at the end of the collection period that was 15,3 , and 10 days for aflatoxin B1 18.12 and 0.716 , and ochratoxin A 3.22 $\mu \mathrm{g} / \mathrm{kg}$ BW, respectively. NA: not analyzed.

$8{ }^{\mathrm{d}}$ Yeast cell wall preparation at low (YCW-L) and high (YCW-H) concentration. See Materials and Methods for details.

$* p<0.05$ between yeast cell wall treatments and controls for each column within each experiment. 


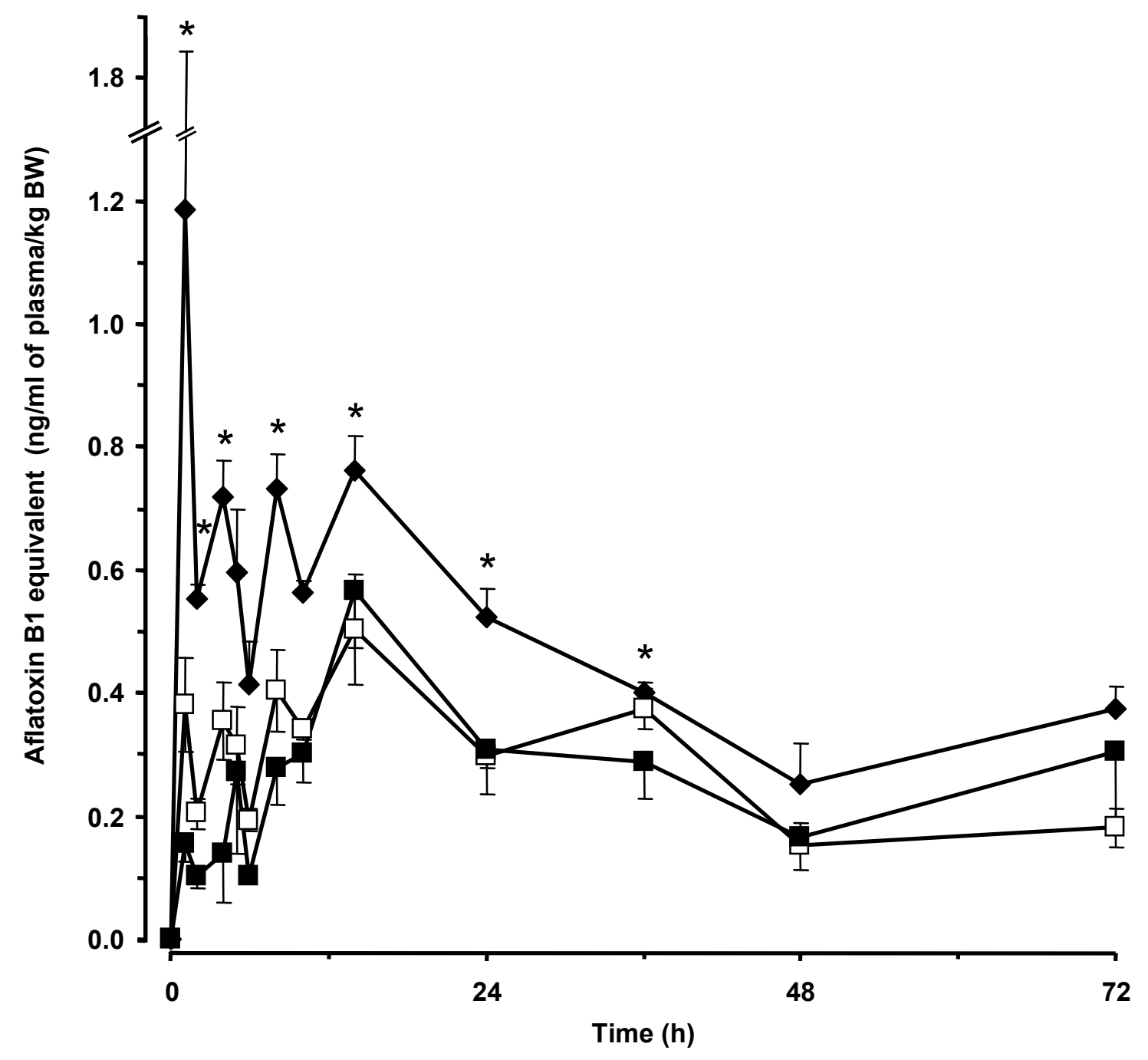

Figure 1. Plasma time-concentration profiles of aflatoxin B1 obtained after a single oral administration of $0.716 \mu \mathrm{g} / \mathrm{kg}$ body weight with ( $\square$ low and $\boldsymbol{\square}$ high) and without $(\diamond)$ co-administration of a yeast cell wall preparation in rats. * indicate $p<0.05$ between groups. 